\title{
Factors Influencing Security Incidents on Personal Computing Devices
}

\author{
Barbara Hewitt, Texas State University, San Marcos, USA \\ iD https://orcid.org/0000-0003-4056-2852 \\ Garry White, Texas State University, San Marcos, USA
}

\begin{abstract}
Organizations expect their employees to connect securely to the organization's computer systems. Often these employees use their personal computers to access the organization's networks. This research explores whether these same employees apply protective security measures to their personal computers. Perhaps these employees behave riskily based on their optimistic bias. Results indicate that while cyber optimistic bias and perceived vulnerability influence individuals to apply more protective security measures, the users still experienced security incidents. Thus, organization are vulnerable to cyber-attacks if they are allowing employees to use personal computers to access these databases.
\end{abstract}

\section{KEYWORDS}

Cyber Optimistic Bias, Perceived Vulnerability, Protective Security Measures, Security Incidents, Technology Optimism

\section{INTRODUCTION}

Organizations spent over $\$ 73.7$ billion protecting their computer systems in 2016 to avoid becoming victims of security breaches with predictions that number will increase to over $\$ 170$ billion by 2020 (Freeman, 2017). Regardless of the vast amounts of money an organization spends, hackers circumvent security measures when users fail to exercise good security practices by responding to phishing emails that harvest personally identifiable information including passwords, visiting untrusted websites, downloading malicious software such as key loggers, or failing to create strong passwords or to apply updates, security patches, and virus protection software (Goel, Williams, \& Dincelli, 2017; Thomas, 2004). For example, Anthem released over 83 million patient insurance records after five employees including the database administrator inadvertently responded to a phishing attack and provided their login credentials to the attackers (Huson \& Hewitt, 2016; Ragan, 2015).

Many organizations allowed their employees to use personal phones (95\%), tablets (67\%), and laptops (93\%) with slightly more than half of the devices being issued by the organization $(51 \%, 30 \%$, and $63 \%$ respectively) (M. A. Harris \& Patten, 2015). While these organizations can enforce policies and security measures on the business owned devices, it is much harder to enforce these measures on the individual's personal devices. Over a third (35\%) of the cell phone users installed third party apps, $31 \%$ of cell phone users and $52 \%$ of laptop users stored authentication credentials in apps, and $13 \%$ of cell phone users and 5\% of laptop users devices were lost or stolen.

Thus, organizations must improve their users' security practices since these users are often the weakest link (Ayyagari, 2012; Bulgurcu, Cavusoglu, \& Benbasat, 2010; Kirkpatrick, 2006; Lee, Lee, 
\& Yoo, 2004; Mitnick, Simon, \& Wozniak, 2006; Rezgui \& Marks, 2008). Sometimes, attacks occur when users access their organizations' systems, databases, and confidential documents using their home computers as opposed to their work computers (Furnell, Bryant, \& Phippen, 2007). Organizations must ensure users comply with information security (IS) policies to minimize incidents since roughly $70 \%$ of employees know where to find their corporate security policies and only $64 \%$ read the policy (Da Veiga, 2016). Major threats to security include employees who do not comply with policies either because they are careless (Siponen, Mahmood, \& Pahnila, 2014; Siponen, Pahnila, \& Mahmood, 2007) or are unaware of how to securely access the organization's systems. To improve users' compliance, IS managers have implemented IS awareness programs (Bauer, Bernroider, \& Chudzikowski, 2017).

To prevent data breaches, organizations should increase the IS awareness of their employees. Subsequently, organizations attempt to increase the employee's security awareness through training and educational courses (Dodge, Carver, \& Ferguson, 2007; He, Ash, et al., 2019; Schultz, 2012) in the hopes of motivating these employees to safeguard their passwords as well as the organization's computer systems and databases (Gage, 1996; Grau, 1984; Siponen, 2000). Several studies explored whether training and education influence security behavior rather than determine if it decrease the number of security incidents one experiences (Britt, 2008; Caldwell, 2016; Pollitt, 2005; Puhakainen \& Siponen, 2010; Sherizen, 1984; Siponen, 2000).

However, security training and awareness programs only effect an employee's knowledge, behavior, and awareness for a short time (Hagen \& Albrechtsen, 2009). White (2012, 2015) found those with more security education still reported experiencing security incidents.

Thus, the need to explore how individuals behave is important. Subsequently one must also identify factors that cause these educated individuals to experience security incidents. Perhaps, underlying perceptions such as optimistic bias, optimism and perceived invulnerability (PV) play a role in security breaches. Optimistic bias often makes a person perceive they are less vulnerable to experience a negative (or more likely to experience a positive) event than their peers (Weinstein, 1980). Trumbo, Meyer, Marlatt, Peek, and Morrissey (2014) suggest that optimism is an individuals' belief that they are less likely to experience a negative outcome than their peers. Schwarzer (1994) described PV as the individual's belief that they will be a victim.

Prior research has attempted to explain security breaches using perceptions of susceptibility, severity, and threat, as well as safeguard costs, safeguard effectiveness, self-efficacy, social norm, and cues to action ((Boysen, Hewitt, McLeod, \& Gibbs, 2019; Carpenter, Young, Barrett, \& McLeod, 2019; Liang \& Xue, 2010; Ng, Kankanhalli, \& Xu, 2009; Vance, Siponen, \& Pahnila, 2012). However, the models that use these constructs do not explain the variance for security behavior (Boysen et al., 2019; Carpenter et al., 2019; Liang \& Xue, 2010; Woon, Tan, \& Low, 2005). While the variance for the security belief model was high, $\mathrm{Ng}$ et al. (2009) indicated a limitation to their study was the limited protective measure they studied (email caution). They did not explore other protective measures such as applying patches or installing malware protection. Recently, cyber optimistic bias (COB) was explored as an antecedent to protective measures (Hewitt \& White, 2020), but the study focused on university students. Thus, this study will explore variables that we believe should be incorporated into those models using a general population from the United States. By exploring whether COB, technical optimism, and PV are impacted by education and subsequently impact an individual's willingness to apply protective measure, this research might explain why these individuals still experience security incidents since many of the other theories do not explain this phenomenon.

\section{LITERATURE REVEIW}

\section{Education}

Organizations often believe that security training will help address security issues (Ballard, 2010; Brown, 1990; Kieke, 2006; White, 2012). Organizations must make their employees more aware 
of information security since the number of security incidents and the costs associated with those breaches are increasing significantly (Mensch \& Wilkie, 2011; Okenyi \& Owens, 2007). Employees were less likely to commit fraud after attending education and training in fraud prevention (Brown, 1990). Individuals were found to change their behavior after completing computer and security courses and training (Albrechtsen \& Hovden, 2010; D’Arcy, Hovav, \& Galletta, 2009; Furnell et al., 2010). For example, employees were more responsive to security incidents (Albrechtsen \& Hovden, 2010), protected their environment (Greenberg, 1986; Kirkpatrick, 2006), stopped misusing an information system (D’Arcy et al., 2009), or modified their behavior (Greenberg, 1986) after attending a security workshop. Training about phishing can lead to users' heightened awareness of phishing attacks, which lowers their risk of becoming a victim (Jansson \& von Solms, 2013). White (2012, 2015) found a relationship between education and security incidents but they found a negative relationship. With both computer and security education and training (CSET), users should be able to recognize security incidents. Additional factors should be considered along with awareness training to lower security incidents by motivating their employees to be security conscience (Gage, 1996; Grau, 1984; Siponen, 2000).

\section{Perceived Vulnerability}

While optimistic bias explains a significant portion of an individual's belief why they are not likely to experience negative events, perceived vulnerability measures one's likelihood of being a victim and impacts their optimistic biases (Lapsley \& Hill, 2010). While vulnerability was first explored in adolescents and young adults, it later expanded to all adults (Quadrel, Fischhoff, \& Davis, 1993). Along with technical optimism and optimistic bias, PV can possibly explain why individuals participate in risky behavior (Lapsley \& Hill, 2010).

\section{Cyber Optimistic Bias}

Optimistic bias is an individual's perception that they are less likely to experience a negative event or more likely to experience a positive effect than others (Weinstein, 1980). Therefore, individuals often take risks regardless of their chances of experiencing a negative outcome whether its contracting a sexually transmitted disease (Chapin \& Pierce, 2012; P. R. Harris, Griffin, \& Murray, 2008; Li, 2008), missing a project deadlines (Korzaan \& Harris, 2017), or experiencing a breach that impacts their online privacy (Cho, Lee, \& Chung, 2010). When an individual perceives he or she has control over the outcomes of negative events, desired outcomes are perceived to be greater than for other subjects. Individuals who experience COB underestimate the likelihood (or probability) that they will experience a security breach, which is an error in judgment (Chapin, 2001; Harris, Griffin, \& Murray, 2008; Weinstein \& Klein, 1996). Weinstein (1980) explains these individuals can be defensive or simply wishful. Even in negative situations, these individuals demonstrate optimistic bias. Regardless, this error in judgment is called optimistic bias and these individuals think other are more likely to experience a bad event (Chapin, 2001; P. R. Harris et al., 2008; Weinstein \& Klein, 1996).

In addition, optimistic bias decreases when fear of becoming a victim increases. For example, people who were victimized previously will exhibit less optimistic bias than people who have not experienced a security breach (Chapin \& Pierce, 2012; Weinstein, 1980). Prior studies explored optimistic bias in healthcare settings or security settings. Chapin and Pierce (2012) found individuals often decide that they possess unique skills or can avoid negative situations such as sexual assault. This paper will explore COB measuring the degree of individuals' believes their chances of experiencing negative events are more (or less) than others as previously examined by Hewitt and White (2020). Individuals are also likely to feel they can circumvent security breaches by behaving differently than others. Hewitt and White (2020) determined that individuals who were cyber optimistically biased also reported that they applied more protective security measures. 


\section{Technical Optimism}

Optimism is individuals' belief that they are less likely to experience a negative outcome than their peers (Trumbo, Meyer, Marlatt, Peek, \& Morrissey, 2014). This optimism can result in behavior that could subsequently affect the number of security protective measures one will apply. The technology readiness index (TRI) as proposed by Parasuraman (2000) explored how individuals believe technology offers individuals more control over their lives. Basically individuals are generally optimistic about technology (Lin \& Hsieh, 2012). This research will further explore how technical optimism impacts and individual's willingness to use protective security measures.

\section{Protective Security Measures}

Protective security measures (PSM) include the use of preventive measures that are utilized by the individual to defend their computer from security breaches and attacks. Computers users apply PSM as a deterrent to ensure their computers are not compromised (Claar \& Johnson, 2012); however, we question whether these measures work. Herath and Rao (2009) determined that end users seldom apply PSM such as updating their antivirus software, applying operating system (OS) patches, backing up their data, or ensuring that their personal fire walls are secure. Williams, Wynn, Madupalli, Karahanna, and Duncan (2014) determined that while individuals install and run software to prevent unauthorized access to their PCs, end users don't update their OS, virus protection software, or application programs or apply patches, leave their computers unattended, and ignore their company's policies about securing sensitive information.

\section{HYPOTHESIS}

LaRose, Rifon, and Enbody (2008) recommend exploring new research to identify behaviors of individuals who use the Internet and encounter security incidents. This study examines the relationship between education, technical optimism, COB, PV, and PSM in regards to how these factors can affect the number of security incidents one experiences.

\section{Education}

Rhee, Kim, and Ryu (2009) used number of years using a computer and the internet to measure computer and internet experience. But these are self-reported and we can't assume that number of years using is similar between different subjects. For this research, to measure experience/expertise, this research used the number of years of CSET that the individual took. PV is one's belief that they will experience an adverse event. It is widely used when exploring computer security Thus, this research suggests that education will positively influence PV.

Hypothesis 1: CSET will have a positive effect on an individual's perceived vulnerability.

Knowledge is a predictor of optimistic bias (Li, 2008). Thus, these individuals often take more risks. These individuals often feel they have control over the outcomes. Hence, as Rhee, Ryu, and Kim (2012) suggest these individual should be exposed to more security training rather than organizations simply applying more security measures. However, organizations should be cautious about how often they require individuals attend training courses as these courses were found to lose their effect over time (Wolf, Haworth, \& Pietron, 2011). This paper will determine how CSET impacts COB.

Hypothesis 2: CSET will have a positive effect on COB. 
Rhee et al. (2012) suggest that organizations should provide more security awareness training to help these individuals overcome the effects of optimism bias. Optimism bias might cause a person trained in security protection to feel more confident than his or her counterparts and subsequently he or she might take more risks. Thus, this research will explore whether these individuals who are more confident experience more security breaches.

Past research has determined that individuals with more education experience more computer security incidents (White, 2012). Thus, this research posits that CSET will impact an individual's ability to recognize that they have experienced a security breach.

Hypothesis 3: CSET will have a positive effect on security incidents.

Technical optimism is defined as when individuals feel they are less likely to experience negative events (Trumbo et al., 2014). Over the years, students were more optimistic about the impact of computers on society. Males were more optimistic than females about the impact of computer technology (Walstrom, Thomas, \& Weber, 2010). Having a sense of less risk, a person, most likely a male, will display riskier behavior, which can lead to security incidents.

Hypothesis 4: CSET will have a positive effect on technical optimism.

\section{Perceived Vulnerability}

Prior research suggests that education may cause individuals to feel less vulnerable and subsequently lower their guard in regard to protecting their computers against viruses and other security threats. Yoon, Hwang, and Kim's (2012) results differed from the findings of earlier studies that explored information security behaviors of working adults and professionals (Chenoweth, Minch, \& Gattiker, 2009; Ng et al., 2009; Workman, Bommer, \& Straub, 2008). An important reason to test this hypothesis is to ensure those who report they are less vulnerable than others (COB) still perceive security threats are real by indicating they are susceptible to breaches. Thus, the following hypothesis will be tested.

Hypothesis 5: PV will have a positive effect on COB.

\section{Cyber Optimistic Bias}

Overconfident individuals often take more risks since they possess protection confidence. They believe that they are more likely than others to experience a positive outcome. Rhee et al. (2012) suggest that organizations should provide more security awareness training to help these individuals overcome the effects of optimism bias rather than simply relying on technological security measures. However, a challenge exists since continued awareness training loses it effectiveness over time (Wolf et al., 2011). Individuals who were previously victimized were less optimistically biased than those who had not previously experienced a negative outcome (Chapin \& Pierce, 2012). Wash and Rader (2015) found that individuals believed that others were at more risk for a security breach than they were.

Optimistic bias even occurs when executives believe that their business associates and other businesses are more likely to experience a security breach than their own company ( $\mathrm{Ng}$ et al., 2009). Optimistic bias might cause a person trained in security protection to feel more confident than their counterparts and subsequently the individual might take more risks. Aytes and Connolly (2004) found that more than $40 \%$ of individuals did not conceive that they will experience a negative event. This research will explore whether these individuals who are more confident or optimistic biased that they will not experience more security breaches.

Individuals who are more educated exude protection confidence and take more risks (Li, 2008). To overcome the effects of optimistic bias, more security awareness training and a better understanding 
of security threats are needed, instead of only relying on implemented security measures (Rhee et al., 2012). Wolf et al. (2011) showed that continued awareness training began to lose its effectiveness overtime. Still, the trained person may feel confident that they are more protected than others are and therefore, willing to take more risks.

Hypothesis 6: COB will have a positive effect on PSM.

\section{Technical Optimism}

When individuals believe they are less likely to be impacted by computers, they are considered to be using technical optimism to not feel threatened by computers. Since technical optimism can result in behavior that could subsequently affect whether individuals apply security measures. Hewitt and White (2020) did not find that technical optimism affected PSM ; however, they were studying students who might not have applied PSM. Students portray more technical optimism than others (Walstrom et al., 2010). Thus, we predict the following hypothesis.

Hypothesis 7: Technical optimism will have a positive effect on PSM.

\section{Protective Security Measures}

Since individuals who are more optimistic bias perceive they will experience less security incidents, they will also probably not apply as many PSM. Thus, these individuals will probably experience more security incidents. Thus, we posit the following hypothesis.

Hypothesis 8: PSM will have a positive effect on the number of security incidents an individual experience on their home computer.

Thus, this paper will explore the model as shown in Figure 1. While Hewitt and White (2020) examined a similar model, their model did not include PV and they examined the relationships between the individual variables. Furthermore, they did not examine the causal relationships between the variables.

\section{RESEARCH METHODOLOGY}

\section{Data Collection}

An online survey was used to test the proposed hypotheses. The items were entered into the online Qualtrics survey instrument. Qualtrics, Inc., an online survey company, provided 1,052 randomly selected subjects from the United States' population to respond to the survey. In order to ensure validation, an item was embedded into the survey to ensure that all respondents were reading the survey questions. To ensure that only those who were working were included, 436 respondents were not working and removed from the analysis. Thus, data for 616 valid response was analyzed.

Over half $(52 \%)$ of the respondents were male. Most of the respondents were under 50 . The majority of the respondents (83\%) had at least some college with almost half of the respondents having a bachelor degree or higher (49\%). While $12 \%$ of the respondents were computer professionals and $3 \%$ were computer security professionals, the majority $(65 \%)$ indicated that they were using a computer on the job. The demographics are shown in Table 1.

\section{Measures}

The model was measured using factors for the elements identified above. Four variables that measure the number of computer classes and security classes taken at either the high school or college level 


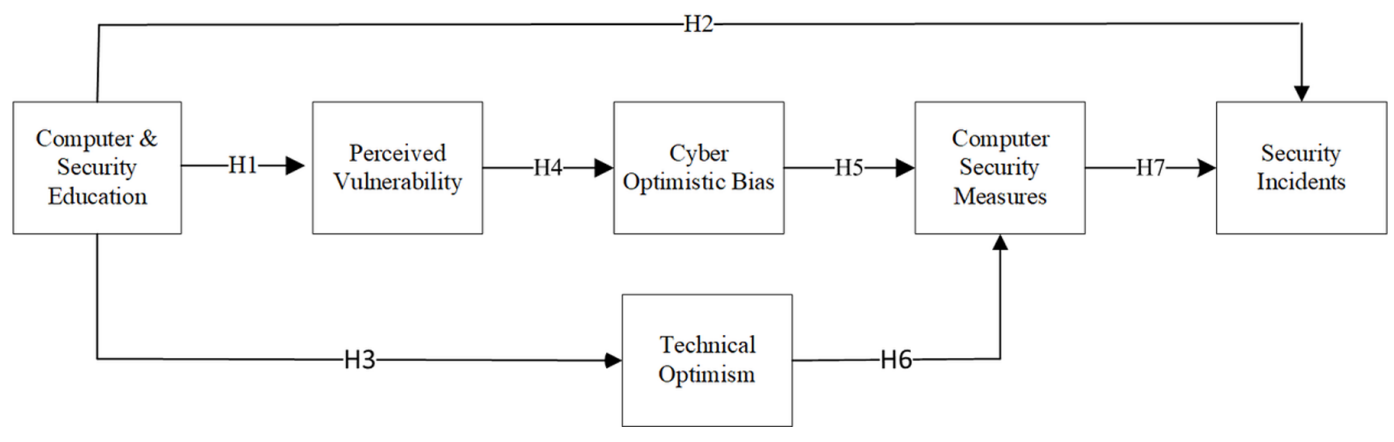

and the number of computer security training sessions were used to measure education as previously used by Hewitt and White (2020). The dependent variable (DV) measured the number of attacks reported on the home computer in the last three years as previously measured by Hewitt and White (2020) and White (2012). The protective measures were measured using measures implemented or updated in the past three years and also adapted from previous studies by Hewitt and White (2020) and White (2012). The remaining items were measured using a 7-point Likert scale. This research modified the COB scale from Chapin (2001) and Chapin and Pierce (2012) studies that examined physical abuse to measure optimistic bias experienced by those experiencing cyber-attacks. Items to measure vulnerability were adapted from the Lapsley and Hill's (2010) vulnerability scale. The variable for technical optimism items was adapted from items used by Parasuraman (2000) and Parasuraman and Colby (2015) who examined individual's readiness to adopt new technologies using the Technology Readiness Index.

Survey items were modified to fit the present environment where necessary. For example, the prior research on vulnerability and optimistic bias were studied in an automobile accidents settings (Lapsley \& Hill, 2010) instead of security breaches. Thus, the items were modified accordingly. For a full copy of the survey, see Appendix B.

\section{DATA ANALYSIS AND RESULTS}

Data analysis was completed in two parts. First, the researchers ensured the validity of the model. Second, the researchers tested the model using partial least squares (PLS) - structural equation modeling (SEM). PLS is good method to use when the researcher is predicting or conducting exploratory research (Garson, 2016). Henseler, Ringle, and Sinkovics (2009) suggest that researchers should use PLS at the earlier stages of model development when testing exploratory models. PLS-SEM allows one to test the impact that variables have on each other simultaneously providing a stronger analysis than other methods such as PLS-regression (Garson, 2016; Korkmazoglu \& Kemalbay, 2012). PLS works well with large or small sample sizes since it uses different methods to perform resampling (Liu \& Zhang, 2014). This resampling whether conducted using bootstrapping or jackknifing provides estimates of stand error of the regression paths. Vilares, Almeida, and Coelho (2010) note that because PLS uses bootstrap resampling, skewed data does not affect the precision of the model estimates. Thus, the data was analyzed using SmartPLS 3.2, which as developed by Ringle et al. (2015). SmartPLS performs a bootstrapping function using sampling with replacement.

For this study, SmartPLS was run using the standard options. Thus, the minimum number of iterations was set to 300 . To determine which items factored on variable, step-wise iterative PLS was performed until all items with factor loadings less than 0.70 were removed. Then bootstrapping was performed using 500 resamples. Each time this was run, the item with the lowest factor loading 
Table 1. Demographics of the respondents

\begin{tabular}{|c|c|c|}
\hline & \# & $\%$ \\
\hline \multicolumn{3}{|l|}{ Gender } \\
\hline Male & 328 & $53 \%$ \\
\hline Female & 288 & $37 \%$ \\
\hline \multicolumn{3}{|l|}{ Age } \\
\hline $18-29$ & 138 & $22 \%$ \\
\hline $30-39$ & 171 & $28 \%$ \\
\hline $40-49$ & 129 & $21 \%$ \\
\hline $50-59$ & 94 & $15 \%$ \\
\hline $60-69$ & 62 & $10 \%$ \\
\hline $70+$ & 22 & $4 \%$ \\
\hline \multicolumn{3}{|l|}{ Education level } \\
\hline High school diploma or GED & 105 & $17 \%$ \\
\hline Some college & 129 & $21 \%$ \\
\hline Associates degree & 86 & $14 \%$ \\
\hline Bachelor's degree & 190 & $31 \%$ \\
\hline Graduate degree & 90 & $15 \%$ \\
\hline Doctorate & 16 & $3 \%$ \\
\hline \multicolumn{3}{|l|}{ Employment Type } \\
\hline Employed full-time & 439 & $71 \%$ \\
\hline Employed part-time & 126 & $20 \%$ \\
\hline Unemployed looking for work & 9 & $1 \%$ \\
\hline Unemployed not looking for work & 6 & $1 \%$ \\
\hline Retired & 27 & $4 \%$ \\
\hline Student & 2 & $0 \%$ \\
\hline Disabled & 7 & $1 \%$ \\
\hline \multicolumn{3}{|l|}{ Computer Usage at Work } \\
\hline Computer professional & 72 & $12 \%$ \\
\hline Computer security professional & 17 & $3 \%$ \\
\hline Computer user on the job & 398 & $65 \%$ \\
\hline Do not use a computer on the job & 129 & $21 \%$ \\
\hline
\end{tabular}

was removed and the PLS calculation was run again. Once all the factor loadings for all items were greater than 0.70 , the validation and reliability tests were compared to acceptable norms as described in the next section.

\section{Measure Validation}

While researchers indicate you do need to ensure goodness of fit (GOF) when studying models using covariance based (CB) -SEM, Hair Jr, Hult, Ringle, and Sarstedt (2016) suggested that users should 
be cautious when reporting goodness of fit when using PLS-SEM such as when using SmartPLS to test goodness of fit in a model. Regardless, SmartPLS provides several measures for goodness of fit. $\mathrm{Hu}$ and Bentler (1998) suggest that standardized root mean square residual (SRMR) less than .10 can be used to determine the goodness of fit. For our model, the SRMR was 0.095 and thus, our model met this measure of goodness of fit. Another measure that can be used is Normal Fit index(NFI). Lohmöller (2013) suggests that values close to 1 are good and .9 is good. Our NFI is 0.9 and thus fit is acceptable.

For analysis purposes, all items were modeled as reflective indicators of the latent constructs. Prior to reviewing the results of the model, the model was assessed for construct reliability, convergent validity, discriminate validity (Anderson \& Gerbing, 1988). To verify reliability, one can use either Composite Reliability or Cronbach's Alpha. The results for both tests must be greater than 0.70 for both tests (Chin, 2010; Fornell \& Larcker, 1981). All Composite Relatability values were greater than the 0.70 threshold as shown in Table 2 . The construct reliability was further confirmed since all Cronbach's Alpha were greater than 0.70 for all items. Thus, construct reliability was met.

Several test were performed in SmartPLS to confirm convergent and divergent validity (Gefen $\&$ Straub, 2005). First, the average variance extracted (AVE) must be greater than 0.5 in support of discriminant validity. As shown in Table 2, all AVE are greater than 0.5. Another comparison used to confirm discriminant validity determines whether the square root of the AVE for a given construct is greater than the correlations of all other constructs both diagonally and horizontally (Fornell \& Larcker, 1981). As shown in Table 3, the diagonal terms represent the square root of the AVE and are greater than the correlations between constructs.

The latent variable factor loadings were computed according to Gefen and Straub (2005). The convergent validity of individual items was determined by verifying all loadings greater than .70 as shown in Appendix A. All items loaded "on-factor" with values greater than .70. All indicators loaded greater "on-factor" than "off-factor" also demonstrating good discriminant validity. These results demonstrated good convergent and discriminant validity.

Another issue that can exist when using surveys is common method bias (CMB). CMB occurs when the survey instrument causes the variation in the responses rather than the actual respondents' beliefs and character (Podsakoff, MacKenzie, Lee, \& Podsakoff, 2003). For example, our survey included subheadings for some of the variables, which could have introduced CMB. Thus, to ensure the survey did not compound any measurement error, several tests can be used to test for CMB. When using PLS-SEM, Kock (2015) suggests one should test for vertical and lateral collinearity. In SmartPLS, the variance inflation factors (VIF) automates these tests for both vertical and lateral collinearity. While Kock (2015) indicates that VIF should be less than 3.3 and any values over 3.3 imply pathological collinearity, Hair, Ringle, and Sarstedt (2013) recommend that the VIF less than 5 is acceptable. As shown in Table 2, the VIF is less than 4 for all items.

\section{RESULTS}

Figure 2 depicts the results of the PLS model testing. The proposed COB model accounts for $42 \%$ of the security incidents that the respondents experience. The results show that CSET positively impacted the individual's PV with a beta coefficient equal to .14 and a p-value of less than $.001(b=.14$, $\mathrm{p}<0.001)$, technical optimism ( $\mathrm{b}=.17, \mathrm{p}<0.001), \operatorname{COB}(\mathrm{b}=10, \mathrm{p}<0.01)$, and security incidents $(\mathrm{b}=.31$, $\mathrm{p}<0.001$ ) providing support for hypotheses $1,2,3$, and 4 . PV positively impacted COB with a beta coefficient of .52 and a p-value less than .001 supporting hypothesis 5. Hypothesis 6 that explored the relationship between COB and PSM was significant. Technical optimism impacted PSM (H7). PSM positively impacted security incidents (H8). The results of the hypotheses tests are presented in Tables 4 and 5.

To further explore the results, responses were analyzed for select variables. For example, one may question whether the individuals actually installed PSM. The majority changed their passwords, 
Table 2. Construct Reliability Results

\begin{tabular}{|c|c|c|c|c|c|c|}
\hline Construct & Items & Loadings & VIF & Alpha & CR & AVE \\
\hline \multirow{5}{*}{$\begin{array}{l}\text { Computer/ } \\
\text { Security } \\
\text { Education }\end{array}$} & CompSecurityUniv & 0.90 & 3.28 & 0.87 & 0.90 & 0.65 \\
\hline & compSecTrain & 0.77 & 1.62 & & & \\
\hline & compUnivCrs & 0.86 & 2.46 & & & \\
\hline & comphscourse & 0.69 & 2.14 & & & \\
\hline & compsechscourse & 0.77 & 2.84 & & & \\
\hline \multirow{3}{*}{$\begin{array}{c}\text { Cyber optimistic } \\
\text { Bias }\end{array}$} & CybOptBias1 & 0.91 & 2.66 & 0.89 & 0.93 & 0.82 \\
\hline & CybOptBias2 & 0.91 & 2.90 & & & \\
\hline & CybOptBias3 & 0.90 & 2.51 & & & \\
\hline \multirow{11}{*}{ Security Incidents } & Incident 1 & 0.73 & 2.11 & 0.94 & 0.95 & 0.62 \\
\hline & Incident 10 & 0.77 & 2.27 & & & \\
\hline & Incident 11 & 0.81 & 2.43 & & & \\
\hline & Incident 12 & 0.79 & 2.43 & & & \\
\hline & Incident 3 & 0.81 & 2.85 & & & \\
\hline & Incident 4 & 0.83 & 3.10 & & & \\
\hline & Incident5 & 0.80 & 2.50 & & & \\
\hline & Incident6 & 0.79 & 2.58 & & & \\
\hline & Incident7 & 0.81 & 2.80 & & & \\
\hline & Incident8 & 0.78 & 2.66 & & & \\
\hline & Incident 9 & 0.72 & 1.91 & & & \\
\hline \multirow{4}{*}{ Technical Optimism } & TechOpt1 & 0.84 & 2.34 & 0.86 & 0.93 & 0.76 \\
\hline & TechOpt2 & 0.88 & 2.50 & & & \\
\hline & TechOpt3 & 0.91 & 3.01 & & & \\
\hline & TechOpt4 & 0.86 & 2.38 & & & \\
\hline \multirow{4}{*}{$\begin{array}{c}\text { Protective Security } \\
\text { Measures }\end{array}$} & Protect 2 & 0.80 & 1.89 & 0.92 & 0.90 & 0.70 \\
\hline & Protect 4 & 0.81 & 1.82 & & & \\
\hline & Protect5 & 0.86 & 2.23 & & & \\
\hline & Protect6 & 0.88 & 2.56 & & & \\
\hline \multirow{4}{*}{$\begin{array}{c}\text { Perceived } \\
\text { Vulnerability }\end{array}$} & Vuln2 & 0.91 & 3.34 & 0.90 & 0.94 & 0.80 \\
\hline & Vuln1 & 0.87 & 2.63 & & & \\
\hline & vuln 3 & 0.89 & 3.55 & & & \\
\hline & vuln4 & 0.91 & 3.96 & & & \\
\hline
\end{tabular}

update their malware/virus protection software, web browser security, privacy setting on web browser and social media accounts as shown in Table 6. Fewer individuals updated their operating system, configured their firewall, or encrypted data on their computer. These findings suggest that these individuals focus on the security features that are less technical. 
Table 3. AVE - Correlation Table

\begin{tabular}{|c|c|c|c|c|c|c|c|c|}
\hline & Mean & SD & $\mathbf{1}$ & $\mathbf{2}$ & $\mathbf{3}$ & $\mathbf{4}$ & $\mathbf{5}$ & $\mathbf{6}$ \\
\hline Computer \& Sec Education (1) & 2.61 & 1.54 & $\mathbf{0 . 8 1}$ & & & & & \\
\hline Perceived Vulnerability (2) & 4.00 & 1.45 & 0.12 & $\mathbf{0 . 8 9}$ & & & & \\
\hline Cyber Optimistic Bias (3) & 4.22 & 1.49 & 0.15 & 0.53 & $\mathbf{0 . 9 1}$ & & & \\
\hline Technical Optimism (4) & 5.18 & 1.32 & 0.12 & 0.15 & 0.26 & $\mathbf{0 . 8 7}$ & & \\
\hline Protect Measures (5) & 2.64 & 1.61 & 0.43 & 0.05 & 0.11 & 0.12 & $\mathbf{0 . 8 4}$ & \\
\hline Security Incidents (6) & 1.87 & 1.45 & 0.51 & 0.00 & 0.53 & 0.04 & 0.57 & $\mathbf{0 . 7 9}$ \\
\hline
\end{tabular}

Figure 2. Resulting Model

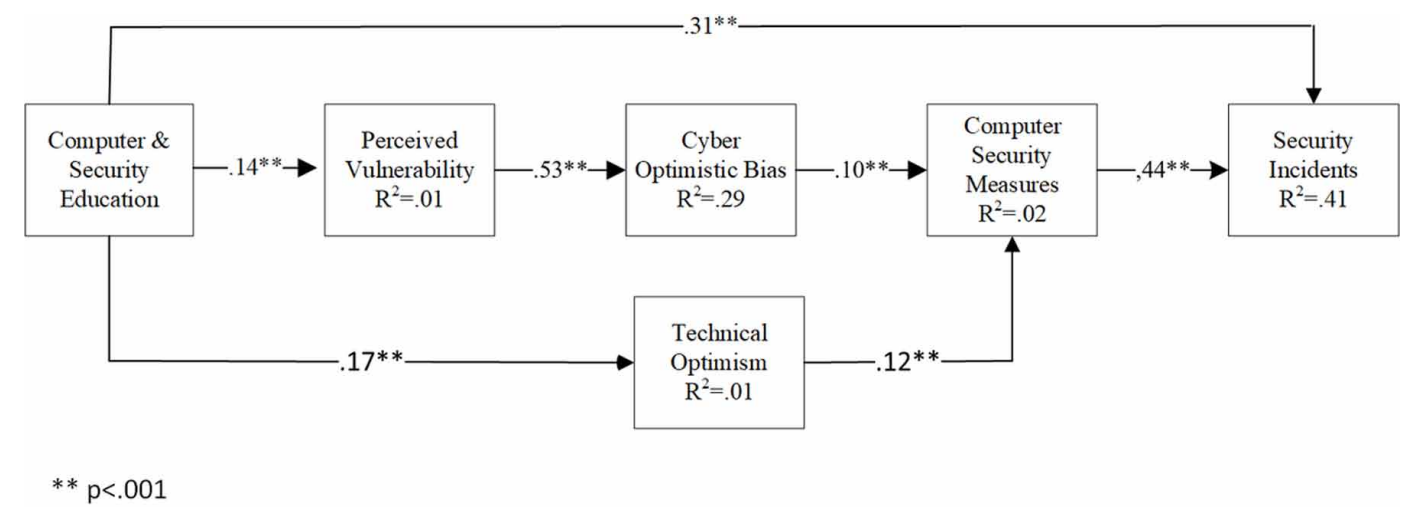

Table 4. Results

\begin{tabular}{|c|c|c|c|c|c|}
\hline & $\begin{array}{c}\text { Original } \\
\text { Sample } \\
(\mathbf{O})\end{array}$ & $\begin{array}{c}\text { Sample } \\
\text { Mean } \\
(\mathbf{M})\end{array}$ & $\begin{array}{c}\text { Standard } \\
\text { Deviation } \\
\text { (STDEV) }\end{array}$ & $\begin{array}{c}\text { T Statistics (IO/ } \\
\text { STDEVI) }\end{array}$ & P Values \\
\hline Comp \& Sec Ed -> Cyber Optimistic Bias & 0.12 & 0.12 & 0.04 & 3.10 & 0.002 \\
\hline Comp \& Sec Ed -> Perceived Vulnerable & 0.1 & 0.27 & 0.04 & 6.25 & 0.000 \\
\hline Comp \& Sec Ed -> Technical Optimism & 0.13 & 0.13 & 0.05 & 2.82 & 0.005 \\
\hline $\begin{array}{c}\text { Cyber Optimistic Bias -> Protective } \\
\text { Measures }\end{array}$ & 0.18 & 0.18 & 0.04 & 4.62 & 0.000 \\
\hline $\begin{array}{c}\text { Perceived Vulnerable -> Cyber Optimistic } \\
\text { Bias }\end{array}$ & 0.10 & 0.10 & 0.04 & 2.39 & 0.017 \\
\hline Protective Measures -> Security Incidents & 0.52 & 0.52 & 0.04 & 12.66 & 0.000 \\
\hline Technical Optimism -> Protective Measures & 0.47 & 0.48 & 0.04 & 11.53 & 0.000 \\
\hline
\end{tabular}

These individuals were also asked how many times they experienced a security breach. Overall, only $20 \%$ of the individuals indicated that they never experienced a security breach. The remaining $80 \%$ of the respondents experienced at least one breach as indicated in Table 7. 
Table 5.Results

\begin{tabular}{|l|c|c|}
\hline \multicolumn{1}{|c|}{ Hypothesis } & Sign & Hypothesis \\
\hline $\begin{array}{l}\text { Hypothesis 1: CSET will have a positive effect on an individual's } \\
\text { perceived vulnerability. }\end{array}$ & $.14, \mathrm{p}<.001$ & Supported \\
\hline Hypothesis 2: CSET will have a positive effect on COB. & $.10, \mathrm{p}<.05$ & Supported \\
\hline Hypothesis 3: CSET will have a positive effect on security incidents. & $.31, \mathrm{p}<.001$ & Supported \\
\hline $\begin{array}{l}\text { Hypothesis 4: CSET will have a positive effect on technical } \\
\text { optimism. }\end{array}$ & $.17, \mathrm{p}<.001$ & Supported \\
\hline Hypothesis 5: PV will have a positive effect on COB. & $.52, \mathrm{p}<.001$ & Supported \\
\hline $\begin{array}{l}\text { Hypothesis 6: COB will have a positive effect on protective security } \\
\text { measures. }\end{array}$ & $.10, \mathrm{p}<.01$ & Supported \\
\hline $\begin{array}{l}\text { Hypothesis 7: Technical optimism will have a positive effect on } \\
\text { PSM. }\end{array}$ & $.17, \mathrm{p}<.001$ & Supported \\
\hline $\begin{array}{l}\text { Hypothesis 8: PSM will have a positive effect on the number of } \\
\text { security incidents that occur on an individual home computer }\end{array}$ & $.44, \mathrm{P}<.001$ & Supported \\
\hline
\end{tabular}

Table 6. Percentage of protective security measures applied

\begin{tabular}{|l|c|c|c|c|c|c|c|}
\hline & \multicolumn{7}{|c|}{ Percentage who applied the security measure a certain number of times } \\
\hline & 0 & 1 & 2 & 3 & 4 & 5 & 6 or more \\
\hline Updated malware lantivirus & $19 \%$ & $22 \%$ & $17 \%$ & $17 \%$ & $6 \%$ & $4 \%$ & $16 \%$ \\
\hline Updated web browser security & $27 \%$ & $22 \%$ & $16 \%$ & $15 \%$ & $7 \%$ & $5 \%$ & $9 \%$ \\
\hline $\begin{array}{l}\text { Updated privacy settings on web } \\
\text { browser }\end{array}$ & $26 \%$ & $21 \%$ & $15 \%$ & $15 \%$ & $7 \%$ & $5 \%$ & $11 \%$ \\
\hline $\begin{array}{l}\text { Reconfigured privacy settings } \\
\text { on social media }\end{array}$ & $31 \%$ & $21 \%$ & $15 \%$ & $12 \%$ & $6 \%$ & $5 \%$ & $10 \%$ \\
\hline $\begin{array}{l}\text { Encrypted data } \\
\text { Configured firewall }\end{array}$ & $56 \%$ & $15 \%$ & $10 \%$ & $6 \%$ & $4 \%$ & $2 \%$ & $7 \%$ \\
\hline Upgrade operating system & $44 \%$ & $12 \%$ & $11 \%$ & $9 \%$ & $5 \%$ & $4 \%$ & $15 \%$ \\
\hline Changed passwords & $11 \%$ & $12 \%$ & $18 \%$ & $17 \%$ & $9 \%$ & $7 \%$ & $26 \%$ \\
\hline
\end{tabular}

Sixteen percent indicated that they had not had any CSET. Thirty-three percent indicated that they had not received any computer security training even though they worked for a company. The results for the computer security and training are shown in Table 8.

\section{DISCUSSION}

CSET impacts one's PV, technical optimism, COB, and the number of security incidents that they experience. Our questions for vulnerability asked whether the individual perceived they were susceptible to security breaches. Thus, this research indicates that the more education these individuals had, they feel less vulnerable to security breaches and less vulnerable than their peers since they also indicated they were less likely to experience a breach than their counterparts. These results support the findings of Hewitt and White (2020) who also found that those who were more COB had more education. CSET impacted their technical optimism as well but the more CSET a person received, 
Table 7. Percentage of individuals experiencing each type of security breach

\begin{tabular}{|l|c|c|c|c|c|c|c|}
\hline \multicolumn{1}{|c|}{ Number of times } & $\mathbf{0}$ & $\mathbf{1}$ & $\mathbf{2}$ & $\mathbf{3}$ & $\mathbf{4}$ & $\mathbf{5}$ & $\mathbf{6 +}$ \\
\hline Victim of ID theft & $72 \%$ & $13 \%$ & $5 \%$ & $4 \%$ & $2 \%$ & $2 \%$ & $2 \%$ \\
\hline $\begin{array}{l}\text { Computer performance due } \\
\text { to Virus/malware }\end{array}$ & $27 \%$ & $23 \%$ & $20 \%$ & $11 \%$ & $7 \%$ & $3 \%$ & $8 \%$ \\
\hline $\begin{array}{l}\text { Data corruption or loss due } \\
\text { to virus/malware }\end{array}$ & $55 \%$ & $16 \%$ & $11 \%$ & $8 \%$ & $4 \%$ & $2 \%$ & $4 \%$ \\
\hline PC controlled by hacker & $78 \%$ & $7 \%$ & $5 \%$ & $3 \%$ & $1 \%$ & $3 \%$ & $2 \%$ \\
\hline $\begin{array}{l}\text { Unauthorized access of } \\
\text { computer }\end{array}$ & $65 \%$ & $14 \%$ & $9 \%$ & $5 \%$ & $2 \%$ & $2 \%$ & $3 \%$ \\
\hline $\begin{array}{l}\text { Internet inaccessible due to } \\
\text { virus/malware }\end{array}$ & $54 \%$ & $18 \%$ & $10 \%$ & $7 \%$ & $4 \%$ & $3 \%$ & $4 \%$ \\
\hline $\begin{array}{l}\text { Download virus/malware via } \\
\text { internet }\end{array}$ & $58 \%$ & $19 \%$ & $9 \%$ & $4 \%$ & $4 \%$ & $3 \%$ & $4 \%$ \\
\hline $\begin{array}{l}\text { Download virus/malware } \\
\text { via email }\end{array}$ & $50 \%$ & $20 \%$ & $12 \%$ & $7 \%$ & $3 \%$ & $3 \%$ & $4 \%$ \\
\hline Victim of phishing attack & $72 \%$ & $10 \%$ & $5 \%$ & $5 \%$ & $3 \%$ & $2 \%$ & $4 \%$ \\
\hline Fallen to a hoax email & $73 \%$ & $9 \%$ & $6 \%$ & $5 \%$ & $3 \%$ & $4 \%$ & $3 \%$ \\
\hline $\begin{array}{l}\text { Privacy problem via social } \\
\text { media }\end{array}$ & $66 \%$ & $12 \%$ & $8 \%$ & $5 \%$ & $4 \%$ & $3 \%$ & $3 \%$ \\
\hline Denial of service attack & $79 \%$ & $7 \%$ & $4 \%$ & $3 \%$ & $2 \%$ & $2 \%$ \\
\hline
\end{tabular}

Table 8. Amount of training or course a respondent received

\begin{tabular}{|c|c|c|c|c|c|}
\hline \multicolumn{2}{|c|}{} & \multicolumn{2}{c|}{ High school } & \multicolumn{2}{c|}{ College/University } \\
\hline & $\begin{array}{c}\text { Computer Security } \\
\text { Training }\end{array}$ & Computer & Security & Computer & Security \\
\hline None & $33 \%$ & $56 \%$ & $34 \%$ & $53 \%$ & $45 \%$ \\
\hline At least 1 course & $67 \%$ & $44 \%$ & $66 \%$ & $47 \%$ & $55 \%$ \\
\hline
\end{tabular}

the more they perceive the less technical optimism they had. These results can possibly be explained as those individuals who are more aware of computers and the security issues through CSET are also more cognizant of the threats exist but feel less vulnerable because they most likely feel confident that they can install mechanisms to prevent any threats. These individuals also indicated that they experienced more security breaches as supported by CSET was also seen to impact the number of security incidents as suggested by Hewitt and White (2020). Perhaps, this is due to the fact that these individuals recognize that security incidents are most likely going to happen.

Those who perceive they are not vulnerable to security incidents are more cyber optimistically biased that they won't experience an attack. Subsequently, those that perceive low vulnerability also perceive they are less vulnerable to cyber-attacks than their peers.

The same individuals who feel cyber optimistically biased perceive they will not experience a security breach, but they still apply more protective measures than their counterparts. As previously determined by Chapin (2001), Weinstein (1980), and Weinstein and Klein (1996), those who feel more at risk than others (optimistic biased) are more likely to behave less risky. Subsequently, as the belief of being a cyber-victim increased (COB, Hypothesis 6), the individual applied more protective behavior. 
Those who believe that computers are a positive part of their life (technical optimism) also apply more security protective measures. This maybe in part due to the fact that they simply recognize that along with the computers being good for them, anything related to computers is good and thus, PSM are good. Thus, they apply more protective measures further supporting the results by Hewitt and White (2020).

PSM include virus and malware protection software, firewalls, and other security measures. Researcher have previously determined that users do not apply PSM to their home computers properly (Aytes \& Connolly, 2004; Bryant, Furnell, \& Phippen, 2008). The majority of researchers explored PSM using a single protective measure such as virus protection software (Liang \& Xue, 2010) or applying security patches (Ng \& Rahim, 2005). White (2012, 2015) also determined that, regardless of whether users installed protective measures, they reported experiencing significant numbers of security incidents. This research supported these prior claims that PSM has a positive impact on the number of security incidents that occur on individuals' home computers.

\section{CONCLUSION}

Security efforts should be focused on people as well as technology, since security is also a people issue (Rezgui \& Marks, 2008). Therefore, we support prior research that suggested the more educated an individual is and the more PSM taken, they are more capable of detecting security incidents. Based on the results of this study, individuals must recognize that they are just as likely to experience a security breach or are not any less than others are regardless of what protective measures they take or how much CSET they possess. Thus, individuals are susceptible to security breaches and should implement security countermeasures to mitigate these risks. In other words, a user's optimism can lead to a false sense of security even when an individual takes protective measures causing them to take risky behavior such as visiting less untrusted websites.

This paper shows that protection/prevention alone is not sufficient. Individuals still experience security incidents. Hence, this paper supports the need for users to be educated in detection and responses to security incidents. Users are going to experience security incidents no matter how much protection they have on their computer. In other words, this study, along with others, shows protection is not an absolute.

As suggested by Hewitt and White (2020), organizations should focus their security efforts on people in addition to security technology. Organizations spend vast amounts of their security budget on technological solutions such as intrusion prevention systems and security professionals; however, they fail to see security as a people issue (Ayyagari, 2012; Bulgurcu et al., 2010; Kirkpatrick, 2006; Mitnick et al., 2006; Neumann, 1999; Rezgui \& Marks, 2008; Thomas, 2004). Organizations must educate their employees to ensure those employees recognize they are part of the issue, and help these employees understand how they can become part of the solution. Designing effective training programs need to follow the suggestions by scientific literature (Bauer et al., 2017) especially since Hagen and Albrechtsen (2009) indicated that employees don't always retain the training. The incorporation of a comprehensive mix of security awareness interventions in training programs is likely to lead to improved levels of behavioral security compliance (Bauer et al., 2017; He, Anwar, et al., 2019; He, Ash, et al., 2019).

This paper contributes to the prior research in several ways. First, it introduces a way to measure multiple PSM that were significant and factored together. Second, it shows that optimistic bias plays a significant role in the reason individuals apply or fail to apply protective measures. It also adds to the literature that explored the role that CSET also play a role in many of the factors that influence one's behaviors such as applying PSM. 


\section{Limitations}

While we obtained a large sample size, general population to gather data for this research, this study still has limitations. For example, we only included vulnerability as a variable from past research that have studied protecting oneself from security. This was in large part due to two reasons. First, we were worried about survey fatigue. Second, we wanted to ensure that those who indicated that they were less likely to experience a security breach still believed that they were vulnerable. A larger sample may show better reliability and/or detect significant smaller negative relationships. Exploring how exposure to the internet during the week and weekend could also have influence on protective measures taken as shown by the relationship between exposure as measured by time on the internet on the weekend and protective measures.

\section{Future Research}

Future research should incorporate cyber optimism bias into the previously studied models such as protection motivation theory or technology threat avoidance theory. This would allow us to see whether $\mathrm{COB}$ plays a role in these theories and possibly improves the variance these models explain.

While other research often uses only one protective measure, this study included multiple items to examine different protective measures. Using protective measures as prescribed here would also add to the literature and determine which protective measures influence security behavior. Additionally, this model could be explored in specific settings such as healthcare where the stakes to keep patient data confidential is high.

\section{ACKNOWLEDGMENT}

This research was supported by College of Business at Texas State University. 


\section{REFERENCES}

Albrechtsen, E., \& Hovden, J. (2010). Improving information security awareness and behaviour through dialogue, participation and collective reflection. An intervention study. Computers \& Security, 29(4), 432-445. doi:10.1016/j.cose.2009.12.005

Anderson, J. C., \& Gerbing, D. W. (1988). Structural equation modeling in practice: A review and recommended two-step approach. Psychological Bulletin, 103(3), 411-423. doi:10.1037/0033-2909.103.3.411

Aytes, K., \& Connolly, T. (2004). Computer security and risky computing practices: A rational choice perspective. Journal of Organizational and End User Computing, 16(3), 22-40. doi:10.4018/joeuc.2004070102

Ayyagari, R. (2012). An exploratory analysis of data breaches from 2005-2011: Trends and insights. Journal of Information Privacy and Security, 8(2), 33-56. doi:10.1080/15536548.2012.10845654

Ballard, C. (2010). Sealing the Breach. Texas Banking, 99(12), 12-13, 20. Retrieved from https://search.proquest. com/docview/847605305?accountid $=5683$

Bauer, S., Bernroider, E. W., \& Chudzikowski, K. (2017). Prevention is better than cure! Designing information security awareness programs to overcome users' non-compliance with information security policies in banks. Computers \& Security, 68, 145-159. doi:10.1016/j.cose.2017.04.009

Boysen, S., Hewitt, B., McLeod, A., \& Gibbs, D. (2019). Refining the Threat Calculus of Technology Threat Avoidance Theory. Commuincations of the Association of Information Systems.

Britt, P. (2008). You've Got Mail and Security Breaches-Email has become business' preferred communication tool, but how secure is it? Information Today, 25(7), 1.

Brown, C. (1990). Crimes of the Vault. Security Management, 34(1), 31.

Bryant, P., Furnell, S., \& Phippen, A. (2008). Improving protection and security awareness amongst home users. Advances in Networks. Computer Communications, 4, 182.

Bulgurcu, B., Cavusoglu, H., \& Benbasat, I. (2010). Information security policy compliance: An empirical study of rationality-based beliefs and information security awareness. Management Information Systems Quarterly, 34(3), 523-548. doi:10.2307/25750690

Caldwell, T. (2016). Making security awareness training work. Computer Fraud \& Security, 2016(6), 8-14. doi:10.1016/S1361-3723(15)30046-4

Carpenter, D., Young, D., Barrett, P., \& McLeod, A. (2019). Refining Technology Threat Avoidance Theory. Communications of the Association for Information Systems, 380-407. doi:10.17705/1CAIS.04422

Chapin, J. R. (2001). Self-protective pessimism: Optimistic bias in reverse. North American Journal of Psychology, 3(2).

Chapin, J. R., \& Pierce, M. (2012). Optimistic bias, sexual assault, and fear. The Journal of General Psychology, 139(1), 19-28. doi:10.1080/00221309.2011.635724 PMID:24836718

Chenoweth, T., Minch, R., \& Gattiker, T. (2009). Application of protection motivation theory to adoption of protective technologies. Proceedings of the 42nd Annual Hawaii International Conference on System Sciences.

Chin, W. W. (2010). How to write up and report PLS analyses. In Handbook of partial least squares (pp. 655-690). Springer. doi:10.1007/978-3-540-32827-8_29

Cho, H., Lee, J.-S., \& Chung, S. (2010). Optimistic bias about online privacy risks: Testing the moderating effects of perceived controllability and prior experience. Computers in Human Behavior, 26(5), 987-995. doi:10.1016/j.chb.2010.02.012

Claar, C. L., \& Johnson, J. (2012). Analyzing home PC security adoption behavior. Journal of Computer Information Systems, 52(4), 20-29.

D'Arcy, J., Hovav, A., \& Galletta, D. (2009). User awareness of security countermeasures and its impact on information systems misuse: A deterrence approach. Information Systems Research, 20(1), 79-98. doi:10.1287/ isre. 1070.0160 
Da Veiga, A. (2016). Comparing the information security culture of employees who had read the information security policy and those who had not. Information \& Computer Security. doi:10.1108/ICS-12-2015-0048

Dodge, R. C. Jr, Carver, C., \& Ferguson, A. J. (2007). Phishing for user security awareness. Computers \& Security, 26(1), 73-80. doi:10.1016/j.cose.2006.10.009

Fornell, C., \& Larcker, D. F. (1981). Structural equation models with unobservable variables and measurement error: Algebra and statistics. JMR, Journal of Marketing Research, 18(3), 382-388. doi:10.1177/002224378101800313

Freeman, L. (2017, June 26). Anthem settles a security breach lawsuit affecting 80M. USA Today.

Furnell, S. M., Bryant, P., \& Phippen, A. D. (2007). Assessing the security perceptions of personal Internet users. Computers \& Security, 26(5), 410-417. doi:10.1016/j.cose.2007.03.001

Furnell, S. M., Clarke, N., von Solms, R., Kruger, H., Drevin, L., \& Steyn, T. (2010). A vocabulary test to assess information security awareness. Information Management \& Computer Security, 18(5), 316-327. doi:10.1108/09685221011095236

Gage, D. (1996). Companies need more security training programs, study finds. Info World Canada, 21(3), 24-25.

Garson, G. D. (2016). Partial least squares: Regression and structural equation models. Statistical Associates Publishers.

Gefen, D., \& Straub, D. (2005). A Practical Guide to Factorial Validity Using PLS-Graph: Tutorial and Annotated Example. Communications of the Association for Information Systems, 16, 91-109. doi:10.17705/1CAIS.01605

Goel, S., Williams, K., \& Dincelli, E. (2017). Got Phished? Internet Security and Human Vulnerability. Journal of the Association for Information Systems, 18(1), 22-44. doi:10.17705/1jais.00447

Grau, J. (1984). Security Education: Something to Think About. Security Management, 28(10), 25-31.

Greenberg, M. (1986). Security Awareness+ Effective Training= Safer Schools. Security Management, 30(8), 47.

Hagen, J. M., \& Albrechtsen, E. (2009). Effects on employees' information security abilities by e-learning. Information Management \& Computer Security.

Hair, J. F. Jr, Hult, G. T. M., Ringle, C., \& Sarstedt, M. (2016). A primer on partial least squares structural equation modeling (PLS-SEM). Sage publications.

Hair, J. F. Jr, Ringle, C. M., \& Sarstedt, M. (2013). Partial least squares structural equation modeling: Rigorous applications, better results and higher acceptance. Long Range Planning, 46(1-2), 1-12. doi:10.1016/j. lrp.2013.01.001

Harris, M. A., \& Patten, K. P. (2015). Mobile Device Security Issues Within the US Disadvantaged Business Enterprise Program. Journal of Information Technology Management, 26(1), 46-57.

Harris, P. R., Griffin, D. W., \& Murray, S. (2008). Testing the limits of optimistic bias: Event and person moderators in a multilevel framework. Journal of Personality and Social Psychology, 95(5), 1225-1237. doi:10.1037/a0013315 PMID:18954204

He, W., Anwar, M., Ash, I., Li, L., Yuan, X., Xu, L., \& Tian, X. (2019). Effects of Evidence-Based Malware Cybersecurity Training on Employees. Academic Press.

He, W., Ash, I., Anwar, M., Li, L., Yuan, X., Xu, L., \& Tian, X. (2019). Improving employees' intellectual capacity for cybersecurity through evidence-based malware training. Journal of Intellectual Capital, 21(2), 203-213. doi:10.1108/JIC-05-2019-0112

Henseler, J., Ringle, C. M., \& Sinkovics, R. R. (2009). The use of partial least squares path modeling in international marketing. In New challenges to international marketing. Emerald Group Publishing Limited. doi:10.1108/S1474-7979(2009)0000020014

Herath, T., \& Rao, H. R. (2009). Protection motivation and deterrence: A framework for security policy compliance in organisations. European Journal of Information Systems, 18(2), 106-125. doi:10.1057/ejis.2009.6

Hewitt, B., \& White, G. L. (2020). Optimistic Bias and Exposure Affect Security Incidents on Home Computer. Journal of Computer Information Systems, 1-11. doi:10.1080/08874417.2019.1697860 
Hu, L., \& Bentler, P. M. (1998). Fit indices in covariance structure modeling: Sensitivity to underparameterized model misspecification. Psychological Methods, 3(4), 424-453. doi:10.1037/1082-989X.3.4.424

Huson, M. L., \& Hewitt, B. (2016). Would Increased Regulation Reduce the Number of Information Breaches? Paper presented at the 2016 49th Hawaii International Conference on System Sciences (HICSS). doi:10.1109/ HICSS.2016.330

Kieke, R. (2006). Survey shows high number of organizations suffered security breach in past year. Journal of Health Care Compliance, 8(5), 49-68.

Kirkpatrick, J. (2006). Protect your business against dangerous information leaks. Machine Design, $78(3), 66$.

Kock, N. (2015). Common method bias in PLS-SEM: A full collinearity assessment approach. International Journal of e-Collaboration, 11(4), 1-10. doi:10.4018/ijec.2015100101

Korkmazoglu, O. B., \& Kemalbay, G. (2012). Econometrics application of partial least squares regression: An endogeneous growth model for Turkey. Procedia: Social and Behavioral Sciences, 62, 906-910. doi:10.1016/j. sbspro.2012.09.153

Korzaan, M., \& Harris, A. (2017). Understanding Predictors of Over-Optimism in IS Project Teams. Journal of Computer Information Systems, 1-8.

Lapsley, D. K., \& Hill, P. L. (2010). Subjective invulnerability, optimism bias and adjustment in emerging adulthood. Journal of Youth and Adolescence, 39(8), 847-857. doi:10.1007/s10964-009-9409-9 PMID:20596815

LaRose, R., Rifon, N. J., \& Enbody, R. (2008). Promoting personal responsibility for internet safety. Communications of the ACM, 51(3), 71-76. doi:10.1145/1325555.1325569

Lee, S. M., Lee, S.-G., \& Yoo, S. (2004). An integrative model of computer abuse based on social control and general deterrence theories. Information \& Management, 41(6), 707-718. doi:10.1016/j.im.2003.08.008

Li, X. (2008). Third-Person Effect, Optimistic Bias, and Sufficiency Resource in Internet Use. Journal of Communication, 58(3), 568-587. doi:10.1111/j.1460-2466.2008.00400.x

Liang, H., \& Xue, Y. (2010). Understanding Security Behaviors in Personal Computer Usage: A Threat Avoidance Perspective. Journal of the Association for Information Systems, 11(7), 394-413. doi:10.17705/1jais.00232

Lin, J.-S. C., \& Hsieh, P.-L. (2012). Refinement of the technology readiness index scale: A replication and cross-validation in the self-service technology context. Journal of Service Management, 23(1), 34-53. doi:10.1108/09564231211208961

Liu, L., \& Zhang, Y. (2014). Enhancing teachers' professional development through reflective teaching. Theory and Practice in Language Studies, 4(11), 2396. doi:10.4304/tpls.4.11.2396-2401

Lohmöller, J.-B. (2013). Latent variable path modeling with partial least squares. Springer Science \& Business Media.

Mensch, S., \& Wilkie, L. (2011). Information security activities of college students: An exploratory study. Academy of Information and Management Sciences Journal, 14(2), 91.

Mitnick, K. D., Simon, W. L., \& Wozniak, S. (2006). The Art of Deception: Controlling the Human Element of Security. Academic Press.

Neumann, P. G. (1999). Risks of insiders. Communications of the ACM,42(12), 160-160. doi:10.1145/322796.322817

Ng, B.-Y., Kankanhalli, A., \& Xu, Y. C. (2009). Studying users' computer security behavior: A health belief perspective. Decision Support Systems, 46(4), 815-825. doi:10.1016/j.dss.2008.11.010

Ng, B.-Y., \& Rahim, M. (2005). A socio-behavioral study of home computer users' intention to practice security. PACIS 2005 Proceedings, 20.

Okenyi, P. O., \& Owens, T. J. (2007). On the anatomy of human hacking. Information Systems Security, 16(6), 302-314. doi:10.1080/10658980701747237

Parasuraman, A. (2000). Technology Readiness Index (TRI) a multiple-item scale to measure readiness to embrace new technologies. Journal of Service Research, 2(4), 307-320. doi:10.1177/109467050024001 
Parasuraman, A., \& Colby, C. L. (2014). An Updated and Streamlined Technology Readiness Index. Journal of Service Research, 18(1), 59-74. doi:10.1177/1094670514539730

Parasuraman, A., \& Colby, C. L. (2015). An updated and streamlined technology readiness index TRI 2.0. Journal of Service Research, 18(1), 59-74. doi:10.1177/1094670514539730

Podsakoff, P. M., MacKenzie, S. B., Lee, J.-Y., \& Podsakoff, N. P. (2003). Common method biases in behavioral research: A critical review of the literature and recommended remedies. The Journal of Applied Psychology, 88(5), 879-903. doi:10.1037/0021-9010.88.5.879 PMID:14516251

Pollitt, D. (2005). Energis trains employees and customers in IT security. Human Resource Management International Digest, 13(2), 25-28. doi:10.1108/09670730510586986

Puhakainen, P., \& Siponen, M. (2010). Improving employees' compliance through information systems security training: An action research study. Management Information Systems Quarterly, 34(4), 757-778. doi: $10.2307 / 25750704$

Quadrel, M. J., Fischhoff, B., \& Davis, W. (1993). Adolescent (in) vulnerability. The American Psychologist, 48(2), 102-116. doi:10.1037/0003-066X.48.2.102 PMID:8442566

Ragan, S. (2015, February 9). Anthem: How does a breach like this happen? CSO, 3.

Rezgui, Y., \& Marks, A. (2008). Information security awareness in higher education: An exploratory study. Computers \& Security, 27(7), 241-253. doi:10.1016/j.cose.2008.07.008

Rhee, H.-S., Kim, C., \& Ryu, Y. U. (2009). Self-efficacy in information security: Its influence on end users' information security practice behavior. Computers \& Security, 28(8), 816-826. doi:10.1016/j.cose.2009.05.008

Rhee, H.-S., Ryu, Y. U., \& Kim, C.-T. (2012). Unrealistic optimism on information security management. Computers \& Security, 31(2), 221-232. doi:10.1016/j.cose.2011.12.001

Ringle, C. M., Wende, S., \& Becker, J.-M. (2015). Smart PLS 3. http://www.smartpls.com

Schultz, E. (2012). Family Computer Crimes. Wall Street Journal. Retrieved from https://www.wsj.com/articles/ SB10000872396390443589304577633460594096538

Schwarzer, R. (1994). Optimism, vulnerability, and self-beliefs as health-related cognitions: A systematic overview. Psychology \& Health, 9(3), 161-180. doi:10.1080/08870449408407475

Sherizen, S. (1984). Successful Security Relies on Corporate Awareness Training. Data Management (Park Ridge, Ill.), 22(12), 10-12.

Siponen, M. (2000). A conceptual foundation for organizational information security awareness. Information Management \& Computer Security, 8(1), 31-41. doi:10.1108/09685220010371394

Siponen, M., Mahmood, M. A., \& Pahnila, S. (2014). Employees' adherence to information security policies: An exploratory field study. Information \& Management, 51(2), 217-224. doi:10.1016/j.im.2013.08.006

Siponen, M., Pahnila, S., \& Mahmood, A. (2007). Employees' adherence to information security policies: an empirical study. Paper presented at the IFIP International Information Security Conference. doi:10.1007/9780-387-72367-9_12

Thomas, K. (2004). Lessons on locking out human error. Financial Times.

Trumbo, C., Meyer, M. A., Marlatt, H., Peek, L., \& Morrissey, B. (2014). An assessment of change in risk perception and optimistic bias for hurricanes among Gulf Coast residents. Risk Analysis, 34(6), 1013-1024. doi:10.1111/risa.12149 PMID:24286290

Vance, A., Siponen, M., \& Pahnila, S. (2012). Motivating IS security compliance: Insights from habit and protection motivation theory. Information \& Management, 49(3), 190-198. doi:10.1016/j.im.2012.04.002

Vilares, M. J., Almeida, M. H., \& Coelho, P. S. (2010). Comparison of likelihood and PLS estimators for structural equation modeling: a simulation with customer satisfaction data. In Handbook of partial least squares (pp. 289-305). Springer. doi:10.1007/978-3-540-32827-8_14 
Walstrom, K. A., Thomas, C. E., \& Weber, A. (2010). Changes in Student Computer Technology Attitudes over 20 Years: 1988 to 2009. Journal of Computer Information Systems, 51(2), 81-86.

Wash, R., \& Rader, E. J. (2015). Too Much Knowledge? Security Beliefs and Protective Behaviors Among United States Internet Users. Paper presented at the SOUPS.

Weinstein, N. D. (1980). Unrealistic optimism about future life events. Journal of Personality and Social Psychology, 39(5), 806-820. doi:10.1037/0022-3514.39.5.806

Weinstein, N. D., \& Klein, W. M. (1996). Unrealistic optimism: Present and future. Journal of Social and Clinical Psychology, 15(1), 1-8. doi:10.1521/jscp.1996.15.1.1

White, G. L. (2015). Education and Prevention Relationships on Security Incidents for Home Computers. Journal of Computer Information Systems, 55(3), 29-37. doi:10.1080/08874417.2015.11645769

White, G. L. (2012). Information Security Education Relationships on Incidents and Preventions: Cyber Assurance Literacy Needs. Proceedings of the Information Systems Educators Conference.

Williams, C. K., Wynn, D., Madupalli, R., Karahanna, E., \& Duncan, B. K. (2014). Explaining Users' Security Behaviors with the Security Belief Model. Journal of Organizational and End User Computing, 26(3), 23-46. doi:10.4018/joeuc.2014070102

Wolf, M., Haworth, D., \& Pietron, L. (2011). Measuring an information security awareness program. The Review of Business Information Systems, 15(3), 9-22. doi:10.19030/rbis.v15i3.5398

Woon, I., Tan, G.-W., \& Low, R. (2005). A protection motivation theory approach to home wireless security. ICIS 2005 Proceedings, 31.

Workman, M., Bommer, W. H., \& Straub, D. (2008). Security lapses and the omission of information security measures: A threat control model and empirical test. Computers in Human Behavior, 24(6), 2799-2816. doi:10.1016/j.chb.2008.04.005

Yoon, C., Hwang, J.-W., \& Kim, R. (2012). Exploring Factors That Influence Students' Behaviors in Information Security. Journal of Information Systems Education, 23(4), 407. 


\section{APPENDIX A}

\section{Table 9. Factor Analysis}

\begin{tabular}{|c|c|c|c|c|c|c|c|}
\hline & $\begin{array}{c}\text { CompSec } \\
\text { Edu }\end{array}$ & $\begin{array}{c}\text { CybOpt } \\
\text { Bias }\end{array}$ & Incidents & Invuln & Prevent & TechOpt & VIF \\
\hline CompSecuni & 0.78 & 0.17 & 0.38 & 0.12 & 0.41 & 0.18 & 1.79 \\
\hline compSecTrain & 0.77 & 0.08 & 0.38 & 0.08 & 0.39 & 0.09 & 2.21 \\
\hline compUnivCrs & 0.90 & 0.19 & 0.46 & 0.12 & 0.43 & 0.17 & 3.97 \\
\hline comphscourse & 0.86 & 0.13 & 0.52 & 0.09 & 0.44 & 0.09 & 3.09 \\
\hline compsechscourse & 0.82 & 0.18 & 0.33 & 0.11 & 0.34 & 0.21 & 2.79 \\
\hline Incident1 & 0.50 & 0.14 & 0.80 & 0.07 & 0.47 & 0.08 & 2.52 \\
\hline Incident 10 & 0.42 & 0.06 & 0.84 & 0.00 & 0.49 & 0.10 & 3.14 \\
\hline Incident 11 & 0.47 & 0.09 & 0.86 & 0.02 & 0.56 & 0.10 & 3.34 \\
\hline Incident 12 & 0.47 & 0.16 & 0.84 & 0.08 & 0.51 & 0.09 & 3.25 \\
\hline Incident3 & 0.43 & 0.04 & 0.86 & 0.00 & 0.51 & 0.07 & 3.61 \\
\hline Incident5 & 0.41 & 0.07 & 0.86 & -0.01 & 0.52 & 0.07 & 3.32 \\
\hline Incident6 & 0.34 & 0.03 & 0.82 & -0.02 & 0.48 & 0.08 & 2.90 \\
\hline Incident7 & 0.38 & 0.06 & 0.85 & -0.01 & 0.49 & 0.07 & 3.48 \\
\hline Incident8 & 0.37 & 0.05 & 0.82 & -0.02 & 0.54 & 0.07 & 3.09 \\
\hline Incident9 & 0.38 & 0.09 & 0.76 & 0.03 & 0.45 & 0.10 & 2.12 \\
\hline Opt1 & 0.13 & 0.29 & 0.07 & 0.14 & 0.13 & 0.87 & 2.56 \\
\hline Opt2 & 0.14 & 0.23 & 0.07 & 0.09 & 0.13 & 0.88 & 2.70 \\
\hline Opt3 & 0.18 & 0.29 & 0.12 & 0.14 & 0.13 & 0.91 & 3.09 \\
\hline Opt4 & 0.17 & 0.29 & 0.09 & 0.16 & 0.13 & 0.86 & 2.21 \\
\hline OptbiasTech1 & 0.14 & 0.91 & 0.02 & 0.52 & 0.08 & 0.33 & 2.83 \\
\hline OptbiasTech2 & 0.19 & 0.93 & 0.09 & 0.48 & 0.15 & 0.24 & 3.17 \\
\hline OptbiasTech4 & 0.17 & 0.90 & 0.15 & 0.47 & 0.16 & 0.29 & 2.61 \\
\hline Prevent2 & 0.37 & 0.08 & 0.48 & 0.02 & 0.85 & 0.11 & 2.31 \\
\hline Prevent4 & 0.37 & 0.12 & 0.50 & 0.03 & 0.84 & 0.14 & 2.16 \\
\hline Prevent5 & 0.51 & 0.15 & 0.57 & 0.08 & 0.88 & 0.13 & 2.50 \\
\hline Prevent6 & 0.42 & 0.14 & 0.52 & 0.04 & 0.88 & 0.13 & 2.66 \\
\hline Vuln2 & 0.08 & 0.49 & -0.04 & 0.91 & 0.03 & 0.16 & 3.56 \\
\hline Vuln1 & 0.08 & 0.50 & -0.04 & 0.88 & 0.06 & 0.14 & 3.01 \\
\hline vuln3 & 0.17 & 0.46 & 0.10 & 0.88 & 0.05 & 0.12 & 2.98 \\
\hline vuln5 & 0.14 & 0.46 & 0.05 & 0.90 & 0.05 & 0.13 & 3.14 \\
\hline
\end{tabular}




\section{APPENDIX B}

\section{Survey}

Please complete the following questions.

Demographic

1. Age years old

2. Gender 1. M 2. F

Comp/Sec Education

3. Please indicate how many courses you have taken for each category.

Number of semester courses in computers while in high school ( 1 year $=2$ semesters $)$

$0123456+$

Number of semester courses in computer/information security while in high school $(1$ year $=2$ semesters) $0123456+$

Number of semester courses in computers at a college or university $0123456+$

Number of semester courses in computer/information security at a college or university

\section{$0123456+$}

Non-academic presentations/training on computer/information security $0123456+$

For the past 3 years, how many times occurred on your personal computer or laptop? (White, 2012, 2015)

\section{Personal/Home Incidents --}

Inc1. Victim from ID theft $0123456+$

Inc2*. Computer "performance" problems due to viruses $0123456+$

Inc3. Data corruption or loss due to viruses $0123456+$

Inc4. PC controlled by hacker $0123456+$

Inc5. Number of unauthorized access to your data $0123456+$

Inc6. Internet became inaccessible due to virus/malware $0123456+$

Inc7. Downloaded a virus via email attachment $0123456+$

Inc8. Downloaded a file off the Internet that contained a virus $0123456+$

Inc9. Victim of phishing $0123456+$

Inc10. Fallen to a hoax email $0123456+$

Inc11. Experienced a privacy problem of social networks $0123456+$

Inc12. Victim of denial of service attack $0123456+$

* Item removed from analysis due to poor factor analysis loadings.

Protective Security Measures

Pro1. upgrade my anti-virus software? $0123456+$

Pro2. increase my security settings of your web browser? $0123456+$

Pro3. increase my privacy settings on my web browser? $0123456+$

Pro4. re-configured my privacy settings on a social network like Facebook?

$0123456+$

Pre5*. encrypt data on my computers? $0123456+$ 
Pre6. configured my firewall? $0123456+$

Pre7*. upgraded my OS with patches? $0123456+$

Pre8*. changed my password? $0123456+$

* Item removed from analysis due to poor factor analysis loadings.

For the following items, indicate 1. Strongly disagree, 2. Disagree, 3. Somewhat disagree, 4. Neither agree nor disagree, 5. Somewhat agree, 6. Agree, 7. Strongly agree.

OPTIMISM (about Technology) (Parasuraman, 2000; Parasuraman \& Colby, 2014)

Please indicate your optimism on the following topics.

OptTec01. New technologies contribute to a better quality of life. 1234567

OptTec02. Technology give me more freedom of mobility. 1234567

OptTec03. Technology gives people more control over their daily lives. 1234567

OptTec04. Technology makes me more productive in my personal life. 1234567

Cyber Optimistic Bias (not happened to me - cyber); item was modified from "abused by an intimate partner" to "cyber-attack." (Chapin, 2001; Chapin \& Pierce, 2012)

Compared to others the U.S. that are similar age as you, answer the following questions. I am less likely to be a:

CyberOptBias1. victim of a cyber-attack 1234567

CyberOptBias2. victim of a virus/malware 1234567

CyberOptBias3. victim of security breach 1234567

CyberOptBias4. victim of identity theft 1234567

Perceived vulnerability (Lapsley \& Hill, 2010)

Vul1*. I am less likely to experience a computer virus than others. 1234567

Vul2. I am unlikely to experience identity theft than others. 1234567

Vul3. A security breach will not happen to me. 1234567

Vul4. Security problems such as identity theft or viruses are not likely to happen to me. 1234567 
Barbara Hewitt is an Assistant Professor in the Department of Health Information Management at Texas State University. She received her Ph.D. in Information Technology from the University of Texas at San Antonio (UTSA), an MBA from Texas State University and her BS in Computer Science also from UTSA She teaches courses such as Healthcare Security, Risk Analysis, Project Management, Information Systems Technology for Healthcare, Practicum, and works with students on their theses. Her research interests include securing information systems including electronic health records, ethics, gamification, and healthy lifestyles including wearables. She has papers in Communication of the Association of Information Systems, Journal of Computer Information Systems, International Journal of Knowledge Management, Journal of Information Privacy and Security. International Journal of Healthcare Technology and Management, Perspectives in Health Information Management, and Data Base.

Garry L. White is an Associate Professor in the Computer Information Systems department at Texas State University in San Marcos, Texas. He holds a MS in Computer Sciences from Texas A \& M University - Corpus Christi and a $P h D$ in Information Systems Education, from The University of Texas at Austin. Professional Certifications from the Institute of Certified Computer Professionals (ICCP) include C.D.P, C.C.P., C.S.P. and Expert Certified in Security Systems. He also holds the Certified Information Systems Security Professional (CISSP). Research interests and work are in the areas of human factors with computer technology, infrastructure security, Internet security, privacy, and global assurance. He has published papers in journals such as the Journal of Computer Information Systems and Journal of Information Systems Education. He was a guest editor for a special issue of the Journal of Information Systems Education; Global Information Security and Assurance in IS Education. 